BMJ Open Sport \& Exercise Medicine

\title{
Integrating physical activity promotion into UK medical school curricula: testing the feasibility of an educational tool developed by the Faculty of Sports and Exercise Medicine
}

\author{
Gemma Pugh (D) , ${ }^{1}$ Patrick O'Halloran, ${ }^{2}$ Laura Blakey, ${ }^{1}$ Hannah Leaver, ${ }^{1}$ \\ Manuela Angioi ${ }^{1}$
}

To cite: Pugh G, 0 'Halloran $P$, Blakey L, et al. Integrating physical activity promotion into UK medical school curricula: testing the feasibility of an educational tool developed by the Faculty of Sports and Exercise Medicine. BMJ Open Sport \& Exercise Medicine 2020;6:e000679. doi:10.1136/ bmjsem-2019-000679

- Additional material is published online only. To view please visit the journal online (http://dx.doi.org/10.1136/ bmjsem-2019-000679).

Accepted 8 March 2020
Check for updates

\section{(c) Author(s) (or their} employer(s)) 2020. Re-use permitted under CC BY-NC. No commercial re-use. See rights and permissions. Published by BMJ

${ }^{1}$ Centre for Sports and Exercise Medicine, Queen Mary University of London, London, UK ${ }^{2}$ School of Clinical and Experimental Medicine, University of Birmingham, Birmingham, UK

\section{Correspondence to} Dr Manuela Angioi; m.angioi@qmul.ac.uk

\section{ABSTRACT}

Background At present education on exercise medicine and physical activity (PA) promotion does not feature heavily within the medical curriculum.

Objectives The purpose of this study was to test the feasibility of a self-directed educational tool (Faculty of Sports and Exercise Medicine (FSEM) exercise prescription booklet) on medical students' understanding of PA in disease management.

Methods Students from 22 UK medical schools were invited to complete a brief online questionnaire before and after being provided access to the FSEM exercise prescription booklet.

Results A total of 205 students responded to the open invitation to participate. At baseline $59 \%$ of students agreed that PA promotion was an important part of a doctor's job with $86 \%$ agreeing that PA was important in the prevention of disease. However, confidence to prescribe PA and knowledge of chief medical officer's adult PA guidelines was low. Following use of the FSEM booklet students' $(n=53)$ knowledge of PA guidelines and confidence to advise patients about PA significantly improved $(p<0.05)$. Correct response answers to case scenarios covering PA in disease management (specifically osteoarthritis and cancer) also improved (32\% and $44 \%$ increase, respectively, $p<0.01$ ).

Conclusion Self-guided educational tools have the potential to improve the exercise prescription skills of undergraduate medical students. Future research should compare different methods of delivering education on PA within medical schools to determine the most effective means of integrating PA into the curriculum.

\section{INTRODUCTION}

Physical inactivity is the fourth leading cause of global mortality ${ }^{1}$ and a major risk factor for a number of medical conditions, ranging from cardiovascular disease to depression. ${ }^{2}$ As such the promotion of physical activity forms the cornerstone of the WHO's global action plan for the prevention and control of noncommunicable disease (NCD). ${ }^{3}$ However,
What are the new findings?

Medical students are aware of the importance of prescribing physical activity to prevent and treat disease but lack the confidence to do so.

- The Faculty of Sports and Exercise Medicine exercise prescription booklet is a potential means by which to enhance medical students' working knowledge of physical activity guidelines and confidence to prescribe exercise as a health tool.

- The Faculty of Sports and Exercise Medicine exercise prescription booklet generally improved medical students' understanding of physical activity in disease management.

How might it impact on clinical practice in the future?

This paper highlights the positive impact of an educational intervention on medical students' beliefs surrounding physical activity in health, knowledge of physical activity guidelines and understanding of physical activity in disease management.

- One challenge in embedding physical activity into the undergraduate curriculum is current curriculum overload. The Faculty of Sports and Exercise Medicine exercise prescription booklet provides one means by which to overcome this problem.

- Successful teaching of exercise prescription to medical students could ensure that future doctors are competent and confident to prescribe exercise and promote physical activity to patients.

inactivity is prevalent, with only $66 \%$ of men and $58 \%$ of women achieving the current recommendations. Doctors are central to supporting patients, particularly those suffering an NCD to change their physical activity behaviour.

At present there is a lack of physical activity promotion across UK medical schools ${ }^{4}$ and 
widespread omission of skills-based teaching designed to equip students to have the confidence and competence to prescribe exercise as a health tool. ${ }^{5}$ In 2012, the average number of hours devoted to teaching physical activity in UK medical schools across the entire undergraduate curricula (years 1-5) was 4.2. ${ }^{5}$ This may explain why only $40 \%$ of final year medical students in Scotland were aware of current physical activity guidelines and $52 \%$ felt they were adequately trained to give advice on physical activity to the general public. ${ }^{6}$

Lectures on exercise medicine and physical activity promotion have been found to be effective at improving medical students' beliefs regarding the importance of physical activity in managing disease and their confidence in physical activity promotion. ${ }^{7}$ However, there is understandable concern that the medical curricula are full with little room for additional contact-teaching material. ${ }^{4}$ Independent learning activities and self-directed educational tools may be an effective means to deliver education on physical activity to undergraduate medical students through an integrated curriculum.

The purpose of this study was to (1) assess UK medical students' knowledge and belief surrounding physical activity and (2) determine the feasibility and impact of an educational intervention (the Faculty of Sports and Exercise Medicine (FSEM) exercise prescription booklet) on medical students' confidence and capability to prescribe physical activity.

\section{METHODOLOGY Study design}

UK medical students were invited to complete an online questionnaire assessing their belief in, knowledge of, confidence and ability to prescribe physical activity in a clinical setting. After completing the initial questionnaire participants were sent the FSEM booklet via email and instructed to review the chapters, case scenarios and learning points within the booklet before completing the follow-up questionnaire. Data were collected in two phases over two academic years: 2015 (phase 1) and 2017 (phase 2).

\section{Participants and recruitment}

UK medical students were contacted via social media portals Facebook and Twitter, medical society bulletins and emails. The social media message, which was posted on the 'Medical Society' Facebook page of UK medical schools contained an advertisement that briefly described the study alongside a link to an online questionnaire created on Google forms. In addition, a convenience sample of students studying intercalated degrees at Queen Mary University of London were invited to participate via a study advertisement circulated by course leaders in February 2017. In order to reduce contamination of the sample, students who have previous qualifications in sports and exercise medicine or sports science will be excluded from analyses.

\section{Measures}

Online supplementary appendix 1 contains the full 17-item 'Exercise Prescription for Medical Students Questionnaire'. Participants were asked to report their gender, medical school, year of study and previous experience in sports science, exercise science or sports and exercise medicine. Beliefs surrounding the benefit of physical activity and confidence to prescribe physical activity were collected using six items previously used by Jones $e t a l^{7}$ and Dunlop et $a l^{6}{ }^{6}$ In order to assess capability to prescribe physical activity students were asked to select the best response answer from four case scenarios covering osteoarthritis, cancer, weight management and a patient with multimorbidity. The questionnaire was assessed for content validity by two clinicians specialising in sports and exercise medicine. The questionnaire was also piloted among a group of 10 medical students for face validity.

\section{FSEM booklet}

The FSEM 'exercise prescription in health and disease: a series of cases for medical students' is contained within online supplementary appendix 2. It is designed to teach exercise prescription to medical students and contains information on generic skills in exercise prescription such as physical activity history taking, behaviour change and condition-specific exercise advice. The booklet was written by 16 consultants, doctors and experts with an interest in physical activity in specific disease areas.

\section{Data analysis}

Statistical analyses were performed in IBM SPSS Statistics V.24.0 for Windows. The responses to questionnaires were tabulated to allow for descriptive and inferential analyses. Median, mode and interquartile ranges were calculated for ordinal variables. Differences between baseline and follow-up were assessed using McNemar's test for dichotomous variables. Statistical significance was set at $\mathrm{P}$ value $<0.05$.

\section{RESULTS}

\section{Study population}

A total of 205 medical students $(\mathrm{n}=132$ females; $\mathrm{n}=73$ males) across 16 UK medical schools completed the baseline questionnaire and were sent the FSEM booklet. Most students $(\mathrm{n}=114,60 \%)$ were in year 2,3 or 4 of medical school; $17 \%(\mathrm{n}=9)$ were studying an intercalated degree; and $8 \%(\mathrm{n}=15)$ identified themselves as studying postgraduate medicine. Fifteen students who had previous qualifications in sports and exercise medicine or sports science were excluded from analysis. A total of 53 students (27\% response rate) reported using the FSEM booklet and completed the follow-up questionnaire. Table 1 depicts the results at baseline.

\section{Beliefs about the role of physical activity}

Table 1 displays students' beliefs, knowledge, and confidence to advice about physical activity. At baseline, $86 \%$ 
Table 1 Medical students' baseline beliefs and confidence about physical activity ( $n=190)$

\begin{tabular}{|c|c|c|c|c|}
\hline Statement & $\begin{array}{l}\% \text { reporting strongly } \\
\text { agree }(n=190)\end{array}$ & Mode & Median & IQR \\
\hline 'Physical Activity is important in preventing disease.' & 86 & 5 & 5 & 0 \\
\hline 'Physical Activity is important in treating disease.' & 30 & 4 & 4 & 1 \\
\hline $\begin{array}{l}\text { 'Advising patients about Physical Activity is an important part of a } \\
\text { doctor's job.' }\end{array}$ & 59 & 5 & 5 & 1 \\
\hline 'I am confident advising patients on Physical Activity.' & 7 & 3 & 3 & 2 \\
\hline $\begin{array}{l}\text { 'I am confident I know the Chief Medical Officer's (CMO) adult Physical } \\
\text { Activity guidelines.' }\end{array}$ & 3 & 1 & 2 & 2 \\
\hline $\begin{array}{l}\text { 'I feel confident that I could raise the issue of Physical Activity with a } \\
\text { patient presenting with an unrelated problem.' }\end{array}$ & 6 & 3 & 2 & 2 \\
\hline
\end{tabular}

Scale for questions: 1=strongly agree, 2=disagree, 3=neither agree nor diagree, 4=agree, 5=disagree.

$\mathrm{IQR}$, Interquartile ranges.

( $\mathrm{n}=163)$ of participants strongly agreed that 'physical activity is important in preventing disease' while $30 \%$ $(\mathrm{n}=57)$ agreed strongly that 'physical activity is important in treating disease'. Fifty-nine per cent $(\mathrm{n}=112)$ agreed with the statement that advising patients about physical activity is an important part of a doctor's job. Very few $(7 \%, \mathrm{n}=13)$ students reported confidence in advising patients about physical activity or raising physical activity with a patient presenting with an unrelated problem $(6 \%, \mathrm{n}=11)$ of students.

\section{Knowledge of physical activity guidelines}

While $90 \% \quad(n=131)$ of students correctly identified the recommended dose of physical activity required for health benefit from a multiple-choice list, only $3 \%(n=5)$ of students reported that they were confident in their knowledge of current physical activity guidelines.

\section{Understanding of physical activity in disease management}

When responding to case scenario questions $53 \% \quad(n=41)$ of students answered correctly regarding what an exercise programme prescribed for someone with osteoarthritis should include. Fifty-two per cent $(n=49)$ correctly identified current American Cancer Society guidelines for physical activity in cancer survivors. Applied knowledge of physical activity recommendations with relation to weight management and hypertension was high with $99 \%$ $(\mathrm{n}=184)$ and $85 \%(\mathrm{n}=161)$ providing correct answers to these case scenarios, respectively.

Table 2 Effect of the Faculty of Sports and Exercise Medicine educational booklet $(n=51)$

\begin{tabular}{|c|c|c|c|}
\hline Statement & Baseline & Post-FSEM booklet & $\begin{array}{l}\text { Exact Sig (two- } \\
\text { tailed) } p \text { value* }\end{array}$ \\
\hline \multicolumn{4}{|l|}{ \%reporting strongly agree } \\
\hline 'Physical Activity is important in preventing disease.' & 82 & 86 & 0.77 \\
\hline 'Physical Activity is important in treating disease.' & 24 & 43 & 0.06 \\
\hline $\begin{array}{l}\text { 'Advising patients about Physical Activity is an important part of a } \\
\text { doctor's job.' }\end{array}$ & 59 & 57 & 1.00 \\
\hline 'I am confident advising patients on Physical Activity.' & 8 & 17 & $<0.01$ \\
\hline $\begin{array}{l}\text { 'I am confident I know the Chief Medical Officer’s (CMO) adult } \\
\text { Physical Activity guidelines.' }\end{array}$ & 2 & 23 & $<0.01$ \\
\hline $\begin{array}{l}\text { 'I feel confident that I could raise the issue of Physical Activity with a } \\
\text { patient presenting with an unrelated problem.' }\end{array}$ & 4 & 17 & 0.03 \\
\hline \multicolumn{4}{|l|}{$\%$ correct response $\mathrm{MCQ}$} \\
\hline Current physical activity recommendations & 72 & 90 & 0.03 \\
\hline Osteoarthritis & 52 & 84 & $<0.01$ \\
\hline Cancer & 13 & 58 & $<0.01$ \\
\hline Weight management & 98 & 90 & 0.21 \\
\hline Hypertension & 60 & 60 & 1.00 \\
\hline
\end{tabular}

Scale for questions: 1=strongly disagree, 2=disagree, $3=$ neither agree nor disagree, 4=agree, 5=strongly agree.

*The $\mathrm{p}$ value was calculated using McNemar's test for repeated measures.

FSEM, Faculty of Sports and Exercise Medicine; MCQ, multiple choice questions. 


\section{Impact of the educational booklet}

Table 2 presents the impact of the FSEM booklet on students' beliefs, knowledge and understanding of the role of physical activity in disease management. Following use of the FSEM booklet, the proportion of students strongly agreeing that physical activity is important in treating disease rose by $19 \%(p=0.06)$. There was a small non-significant increase in the number of students agreeing with the view that physical activity was important in preventing disease ( $\%$ diff: $4 \%, \mathrm{p}=0.77$ ). The proportion agreeing with the statement that advising patients about physical activity is an important part of a doctor's job dropped slightly (\% diff: $-2 \%, \mathrm{p}=0.90$ ).

The FSEM booklet had a significant impact on students' reported confidence to advise patients about physical activity (\% diff: $8 \%, \mathrm{p}<0.01$ ) and raise physical activity in conversation with a patient ( $\%$ diff: $13 \%, \mathrm{p}<0.01)$. This number of students able to correctly identify chief medical officer's physical activity guidelines from a multiple-choice list rose to $90 \%$ (\% diff: $18 \%, \mathrm{p}=0.03$ ) and coincided with a reported improvement in knowledge of the guidelines (\% diff: $21 \%, \mathrm{p}<0.01$ ). Following reading and completing the case scenarios contained within the FSEM booklet correct response answers to questions covering osteoarthritis and cancer significantly improved $(\mathrm{p}<0.01)$.

\section{DISCUSSION}

This study investigated UK medical students' knowledge and belief surrounding physical activity and determined the effect of an educational tool on their understanding of physical activity in disease management. Results suggest that UK medical students are aware of physical activity guidelines and recognise the importance of exercise in disease prevention but tend not to recognise the importance of physical activity in disease management or feel they have the confidence to address physical activity with patients in practice. These findings are unsurprising especially given that medical students are more likely to receive education on smoking, alcohol consumption and drug use in comparison to physical activity. ${ }^{8}$

Akin to public health campaigns to improve overall population understanding of the role of physical activity in disease prevention, ${ }^{9}$ efforts must now be made to ensure medical students are aware of the evidence indicating physical activity has a role in chronic disease management and reduction of risk of recurrence for multiple conditions. ${ }^{10}$ The knowledge gap highlighted within this study is reflective of previous cross-sectional reports ${ }^{56}$ and provides further stimulus for physical activity to be embedded within the undergraduate medical curriculum as a formal training component. ${ }^{11}$

Students' working knowledge of physical activity prescription for the general population, patients with cancer and patients with osteoarthritis generally improved after use of the FSEM booklet. The proportion recognising that physical activity is important in the treatment of disease also increased. These findings are reflective of
Jones and colleagues' 2013 study which investigated the impact of a single lecture on medical students' attitude towards and knowledge of physical activity promotion and exercise prescription. ${ }^{7}$ In addition to change in attitude towards physical activity, a three-round Delphi survey conducted among Thai medical schools ${ }^{12}$ and a systematic review of existing physical activity education initiatives being carried out in medical schools ${ }^{13}$ both highlight the importance of improving medical students' self-efficacy to conduct physical activity counselling.

Within the UK, steps are being made towards a consistent approach to embedding physical activity into the undergraduate medical curriculum with 'Movement for Movement' resources being endorsed by Public Health England and Sport England. ${ }^{14} 15$ Driven by strong leadership and engagement complete implementation of the Movement for Movement programme has been achieved by Lancaster Medical School. ${ }^{14}$ This case reiterates the importance of support from medical school deans and essential stakeholders for there to be inclusion of lifestyle medicine in the undergraduate medical curriculum. ${ }^{16}$ More recently, as part of the Moving Healthcare Professionals programme (MHPP) 74\% $(n=26 / 35)$ of medical schools in England have agreed to implement physical activity modules and education into the undergraduate curricula or have already done so. ${ }^{17}$ The MHPP has adopted a whole education approach to embedding physical activity into clinical practice including the delivery of undergraduate education and continued professional development resources for qualified healthcare practitioners. The spiral curriculum approach (whereby a common learning point is embedded across multiple different topics and learning experiences) aims to widen the reach of physical activity education beyond those who have personal interest in the topic. In an attempt to be as practical and cost-effective as possible, much of the MHPP is delivered through e-learning. Compulsory self-directed e-learning may be one potential solution to integrate physical activity into the undergraduate medical curriculum without creating additional undue pressure on timetabling or curriculum space. ${ }^{18}$

Student-led advocacy, peer-led interest groups and evidence-based resources have been identified as other essential factors required for curricula change in this area. ${ }^{12}$ Moreover, a systematic review of physical activity counselling programmes delivered in American medical schools suggests education programmes providing experiential learning opportunities could have the greatest impact on trainees' knowledge, skill set and clinical behaviour. ${ }^{15}$ Opportunities to practise physical activity advice provision in simulated encounters or in a supervised clinical setting would be beneficial to students. Most notably, however, is the role of assessment as a driver for students to acquire knowledge and skills. ${ }^{16}$ Without questions on physical activity being included within medical school exams it is unlikely physical activity promotion (or general lifestyle medicine) will be considered by students as a core competency. 


\section{Limitations and future research}

Of the original 205 who responded to the baseline questionnaire and were sent the FSEM booklet, only 53 (27\%) completed the follow-up survey, the exact response rate cannot be calculated due to the snowball nature of recruitment. This drop-off likely represents response bias among the convenience sample who participated. Future work would be strengthened by a larger sample of data from medical students from across a wider range of universities at different stages of their education. However, the mix of students from different institutions and medical school years (clinical vs non-clinical) does allow some generalisability of results in comparison to previous education-based intervention studies which have been predominantly conducted at single institutions within the USA. ${ }^{13}$ Using G*Power (V.3.1, Mac) and a sample size of 53 with a power of 0.8 and alpha error probability of 0.05 a fully powered study would require 415 students to detect small differences between groups $(\mathrm{d}=0.37)$. This study should be considered a pilot study as it was carried out with intent to test the feasibility of using the FSEM booklet as a brief educational tool. The size of the sample within this study ( $\mathrm{n}=205$ survey responses, $\mathrm{n}=53$ education tools use) is not dissimilar to existing cross-sectional studies conducted in the UK investigating medical students' knowledge of specific topics (eg, ref 19 $\mathrm{n}=251$; ref $20 \mathrm{n}=280$; and ref $21 \mathrm{n}=167$ ) and those testing the impact of educational interventions (eg, ref $7 \mathrm{n}=58$ ).

As yet there have been no cluster randomised controlled trials or long-term evaluations determining the effect of educational interventions or curriculum changes on medical students' skills to promote physical activity as part of everyday medical practice. ${ }^{13}$ Our study, akin to other studies in the area, has relied on self-report and Likert-type measures to determine impact. Future work should include objective evaluations of change in physical activity promotion behaviour, knowledge and skills. This could be achieved via case study tests, supervisor checklists and portfolio logs. Opportunities for medical students to address their own physical activity behaviours and receive teaching on conceptual models of behaviour change also require exploration. A 4-year intervention of this type, conducted at Emory University School of Medicine to improve medical students' health behaviour, found that the intervention positively affected medical students' perception of health promotion and improved their patient counselling skills. ${ }^{22}$ If doctors are to be credible advocates for physical activity, they need to be visible champions too.

\section{CONCLUSION}

Educational tools such as the FSEM booklet have the potential to improve medical students' knowledge and confidence to prescribe physical activity without creating additional curriculum burden. Innovative teaching methods which do not place undue burden on the curriculum require further exploration.

\section{Twitter Gemma Pugh @GemmaPugh2}

Acknowledgements We would like to acknowledge Dr Gurjit Bhogal for his contribution creating the FSEM booklet and for contributing to the discussion of the study design at the outset.

Contributors PO developed the FSEM intervention booklet. MA, HL and LB collected the data. GP analysed the data and produced the manuscript.

Funding The authors have not declared a specific grant for this research from any funding agency in the public, commercial or not-for-profit sectors.

Competing interests None declared.

Patient consent for publication Not required.

Ethics approval Ethical consent was granted by the Queen Mary University of London Ethics Committee (QMREC2014/24/118).

Provenance and peer review Not commissioned; externally peer reviewed.

Data availability statement All data relevant to the study are included in the article or uploaded as supplementary information.

Open access This is an open access article distributed in accordance with the Creative Commons Attribution Non Commercial (CC BY-NC 4.0) license, which permits others to distribute, remix, adapt, build upon this work non-commercially, and license their derivative works on different terms, provided the original work is properly cited, appropriate credit is given, any changes made indicated, and the use is non-commercial. See: http://creativecommons.org/licenses/by-nc/4.0/.

ORCID iD

Gemma Pugh http://orcid.org/0000-0002-0608-0967

\section{REFERENCES}

1 Lear SA, Hu W, Rangarajan S, et al. The effect of physical activity on mortality and cardiovascular disease in 130000 people from 17 high-income, middle-income, and low-income countries: the PURE study. Lancet 2017;390:2643-54.

2 Bull FC, Bauman AE. Physical inactivity: the "Cinderella" risk factor for noncommunicable disease prevention. $J$ Health Commun 2011;16 Suppl 2:13-26.

3 Durstine JL, Gordon B, Wang Z, et al. Chronic disease and the link to physical activity. J Sport Health Sci 2013;2:3-11.

4 Public Health England \& Sport England. Embedding physical activity in the undergraduate curriculum. Moving healthcare professionals programme. Authors on behalf of Exercise Gates AB \& Ritchie IK, 2018.

5 Weiler R, Chew S, Coombs N, et al. Physical activity education in the undergraduate curricula of all UK medical schools: are tomorrow's doctors equipped to follow clinical guidelines? Br J Sports Med 2012;46:1024-6.

6 Dunlop M, Murray AD. Major limitations in knowledge of physical activity guidelines among UK medical students revealed: implications for the undergraduate medical curriculum. $\mathrm{Br} J$ Sports Med 2013;47:718-20.

7 Jones PR, Brooks JHM, Wylie A. Realising the potential for an Olympic legacy; teaching medical students about sport and exercise medicine and exercise prescribing. $\mathrm{Br} J$ Sports Med 2013;47:1090-4.

8 Hauer KE, Carney PA, Chang A, et al. Behavior change counseling curricula for medical trainees: a systematic review. Acad Med 2012;87:956-68.

9 Fredriksson SV, Alley SJ, Rebar AL, et al. How are different levels of knowledge about physical activity associated with physical activity behaviour in Australian adults? PLoS One 2018;13:e0207003.

10 Jaques R, Loosemore M. Sports and exercise medicine in undergraduate training. Lancet 2012;380:4-5.

11 Osborne SA, Adams JM, Fawkner S, et al. Tomorrow's doctors want more teaching and training on physical activity for health. $\mathrm{Br} \mathrm{J}$ Sports Med 2017;51:624.2-5.

12 Wattanapisit A, Petchuay P, Wattanapisit S, et al. Developing a training programme in physical activity counselling for undergraduate medical curricula: a nationwide Delphi study. $B M J$ Open 2019;9:e030425.

13 Dacey ML, Kennedy MA, Polak R, et al. Physical activity counseling in medical school education: a systematic review. Med Educ Online 2014; 19:24325

14 Gates AB, Swainson MG, Isba R, et al. Movement for movement: a practical insight into embedding physical activity into the undergraduate medical curriculum exemplified by Lancaster medical school. Br J Sports Med 2019;53:609-10. 
15 Gates AB, Kerry R, Moffatt F, et al. Movement for movement: exercise as everybody's business? Br J Sports Med 2017;51:767-8.

16 Phillips E, Pojednic R, Polak R, et al. Including lifestyle medicine in undergraduate medical curricula. Med Educ Online 2015;20:26150.

17 Brannan M, Bernardotto M, Clarke N, et al. Moving healthcare professionals - a whole system approach to embed physical activity in clinical practice. BMC Med Educ 2019;19:84.

18 Sinclair PM, Kable A, Levett-Jones T, et al. The effectiveness of Internet-based e-learning on clinician behaviour and patient outcomes: a systematic review. Int J Nurs Stud 2016;57:70-81.

19 Hearn J, Marwood M. Evaluating mental health literacy in medical students in the United Kingdom. J Mental Health Train 2019;14.
20 Barber S, Brettell R, Perera-Salazar R, et al. UK medical students' attitudes towards their future careers and general practice: a crosssectional survey and qualitative analysis of an Oxford cohort. BMC Med Educ 2018:18:160.

21 Atiiga PA, Drozd M, Veettil R. Awareness, knowledge, and interest in interventional radiology among final year medical students in England. Clin Radiol 2017;72:795.e7-e12.

22 Frank E, Elon L, Hertzberg V. A quantitative assessment of a 4-year intervention that improved patient counseling through improving medical student health. MedGenMed 2007;9:58. 